\title{
A FORMAÇÃO DO PROFESSOR PARA AS ESCOLAS RURAIS NO PARANÁ NO CONTEXTO DAS POLÍTICAS DE EDUCAÇÃO NACIONAIS E INTERNACIONAIS
}

\author{
Maria Elisabeth Blanck Miguel \\ Pontifícia Universidade Católica do Paraná \\ maria.elisabeth@pucpr.br
}

\section{RESUMO}

O texto trata da formação de professores no Paraná, no período de 1946 a 1961, especialmente a formação proporcionada pelos cursos normais regionais. Estes cursos objetivando capacitar o professor para formar o aluno das zonas rurais, procuravam, sobretudo prepará-lo para formar o futuro trabalhador rural, por meio da educação escolar. Os cursos normais regionais seguiam as diretrizes da Lei Orgânica do Ensino Normal (1946), mas em nível internacional atendiam às Recomendações da UNESCO. A organização, as disciplinas e, sobretudo as práticas ensinadas, inseriam-se nas políticas internacionais. O modelo das missões culturais trazido do México por Lourenço Filho e sugerido pelo INEP, inspirou atividades educativas nos cursos normais e coadunava-se com tais políticas. A educação dos professores, pensada pelos organismos internacionais, gestava-se no seio da reestruturação capitalista do período pós $2^{\mathrm{a}}$ guerra mundial, e no Paraná, desenvolvia-se impulsionada pela colonização do Estado com o avanço da lavoura cafeeira.

Palavras- chave: formação de professores; Curso Normal Regional; Recomendações da UNESCO

\section{THE EDUCATION OF TEACHERS TO RURAL SCHOOLS IN THE STATE OF PARANA IN THE CONTEXT OF NATIONAL AND INTERNATIONAL POLICIES}

\begin{abstract}
The text argues the education of teachers in the state of Parana during the period from 1946 to 1961 , mainly the education provided by local normal courses. In order to capacitate the teachers to educate the students of rural areas, those courses aimed to prepare them to become rural workers through school. Those local normal courses followed the policies of the Organic Law of Normal Education (1946), although they were under UNESCO recommendation in an international level. The organization, the disciplines and most of all, the practices that were taught followed international policies. The model of the cultural missions that was brought from Mexico by Lourenço Filho and recommended by INEP has inspired educational activities in the normal courses and has incorporated those policies. The education of teachers meant by international organisms rested on the basis of the capitalist restructuration of the period right after the Second World War and it was developed by the colonization in the State with the progress of coffee farming in the state of Parana
\end{abstract}

Keywords: Teachers Education; Local Normal Course; UNESCO Recommendations. 
Este texto tem o objetivo de aprofundar as reflexões sobre a relação entre a formação dos professores para as zonas rurais, as políticas de educação e suas vinculações com as Recomendações da UNESCO tomando como objeto particular de pesquisa, a formação de professores no Paraná, sua articulação com as Recomendações da UNESCO, bem como a influência nas orientações para as práticas pedagógicas ensinadas nesses Cursos.

No período de 1946 a 1961 o Paraná completou a ocupação de seu território. Os municípios que surgiram no período traziam consigo as demandas da população, dentre as quais as de escolas. O governo paranaense, atendendo às diretrizes das Leis Orgânicas de Educação Primária e Normal (1946) propôs cursos de formação de professores em nível de Normal Regional, cujo currículo e atividades objetivavam formar o professor como aquele que iria educar o habitante das zonas rurais para a melhor produção e adequação às normas de desenvolvimento dentro da ordem capitalista.

A formação do professor para o meio rural já havia iniciado em 1930 e teve continuidade até 1971; desenvolveu-se procurando atender às demandas da população que cresciam na medida em que se multiplicavam os municípios em função da lavoura cafeeira enquanto expansão da lavoura paulista: as plantações de café estenderam-se além da divisa do rio Paranapanema instalando-se em terras paranaenses. Porém, outros fatores concorreram para que tal acontecesse: as políticas estaduais do governo do Paraná para a colonização do Estado, ou seja, políticas de migração e imigração dirigidas; a transformação do capital agrícola do café em capital financeiro (beneficiamento e comercialização); as políticas nacionais vinculadas às políticas internacionais de reordenação do mundo ocidental capitalista sob a égide norte-americana no período pós $2^{\mathrm{a}}$ guerra mundial. As políticas estaduais, assim como as nacionais constituiam-se em expressões regionais e nacionais do arranjo mais amplo do qual tomaram parte outros países da América Latina seguindo as Recomendações da UNESCO.

Os Cursos Normais Regionais (Lei Orgânica do Ensino Normal ${ }^{1}$ ) que objetivavam, sobretudo, a formação no local de trabalho, de professores já em serviço cuja profissionalização formal era incompleta ${ }^{2}$, tinham ainda como finalidade, $o$ atendimento às necessidades dos alunos nos seus lugares de origem. Estas necessidades eram entendidas pelo governo, como as vinculadas à produção, ou mais especificamente às atividades de agricultura e pecuária. As propostas educacionais então implantadas assumiam tais finalidades como objetivos educacionais.

Em 1936, a UNESCO, na Recomendação $n^{\circ} 8$ concernente à Organização do Ensino Rural, fazia várias recomendações aos Ministérios da Instrução Pública que orientaram o ensino rural também no Brasil. Dentre elas, a de que fosse assegurado o mesmo nível de qualidade de educação para as zonas rurais como o proporcionado às escolas das zonas urbanas dando condições aos alunos das zonas rurais, quando da conclusão dos estudos, de acesso ao ensino médio:

1) Que l'éducation donnée aux enfants des écoles rurales ne soit en principe, infériure en rien à celle qui est donnée aux enfants des écoles urbaines, et leur permette l'accès des écoles du second degré; (UNESCO. Recommandations, 1977, p. 18)

Recomendava ainda, que os professores procurassem, na medida do possível, remediar as condições desfavoráveis das zonas rurais e que os professores adaptassem os programas às condições locais, em particular aplicassem os "centros de interesse" (uma das metodologias da Pedagogia da Escola Nova), ligados aos motivos da zona rural. 
2) Que, dans la pratique et pour assurer une plus exacte justice dans le domaine de l' education, on s'efforce de remédier dans toute la mesure du possible aux conditions défàvorables dans lesquelles peut se trouver l'école rurale;

3) Qu'un meme niveau d'instruction soit assure dans les écoles rurales et dans les écoles urbaines, les maîtres ayant naturellement le devoir d'adapter les progammes aux conditions locales et, en particulier de tirer leurs "centres d'intérêts" du lieu dans lequel vivent leurs élèves; (UNESCO. Recommandations, 1977, p.18)

Além da recomendação da utilização dos "centros de interesse", outros princípios da Pedagogia da Escola Nova e recursos didáticos desta concepção eram sugeridos para as escolas das zonas rurais, tais como: o estudo da realidade próxima do estudante, ou seja, o estudo do meio rural.

6) Que, dans les programmes généraux des écoles primaires, une place sufisante soit faite aux notions qui concernent la vie rurale;

7) Que les instituteurs ruraux utilisent les facilites didactiques particulières que leur offre le milieu pour donner à leur enseignement un caractère concret et vivant de nature à developper chez leurs élèves le goût de la vie rurale. (UNESCO. Recommandations, 1977, p.18)

Algumas recomendações da UNESCO de 1936, somente seriam possíveis mais tarde, nas décadas de 80 e 90, quando da implantação das políticas de municipalização, como a criação de escolas centrais reduzindo as escolas rurais multisseriadas:

9) Que, pour permettre aux écoles rurales de donner aux enfants toute l'éducation à laquelle ils ont droit, on limite très strictement le nombre maximum des élèves à admettre dans les écoles à classe unique;

10) Qu'on s'efforce, par la création d'écoles “centrales", de reéduire dans la mesure du possible, le nombre des écoles à classe unique; que, si elles sont conservées pour les enfants les plus jeunes, des classes "centrales" soint à tout le moins créés pour les garçons et pour les filles plus âgés; que les services de transport et les cantines nécessaries à cet effet soient organisés; (UNESCO. Recommandations, 1977, p. 18)

Ainda, reforçava a recomendação da garantia dos mesmos níveis de formação para os professores das zonas rurais e das zonas urbanas, além de sugerir a existência e utilização pelas escolas, de instituições periescolares, bibliotecas itinerantes, radio rural, cinema educativo, ensino por correspondência:

12) Que les maîtres d'écoles rurales ne soint pas infériorisés par rapport à ceux des écoles urbaines;

Qu'à cette fin, une formation générale et professionnelle de même niveau soit donnée aux uns et aux autres soit dans des établissements communs, soit dans des établissements spéciaux pour maîtres urbains ou maîtres ruraux une place siffisante étant em tout cas assurée aux notions rurales, et pour les institutrices, aux notions ménagères;

$[\ldots]$ 
15) Que l'action de l'école soit completée ou fàcitée par l'organisation d'oeuvres périscolaires et postscolaires, telles que les cercles de jeunes fermiers ou de jeunes fermières, les bibliothèques itinérantes, les séances de radio rurale ou de cinématographe éducatif, les missions pédagogiques et culturelles, l'enseignement par correspondance, etc. (UNESCO. Recommandations, 1977, p. 19) (grifo nosso)

A preocupação em proporcionar formação equivalente aos mestres formados nos cursos normais colegiais e normais regionais, ao menos nas propostas educacionais paranaenses foi buscada, por meio do currículo proposto para as Escolas Normais Regionais. Este currículo, além das matérias que o compunham, sugeria toda uma vasta gama de atividades que objetivavam dar ao professor uma sólida formação pedagógica 3 .

$\mathrm{Na}$ proposta implantada pelo governo paranaense por meio dos Cursos Normais Regionais na vigência do primeiro governo de Moysés Lupion $(1947$ - 1951), atendendo ao prescrito no item 15, identifica-se a presença do modelo das missões pedagógicas e culturais (les missions pédagogiques et culturelles) como uma das atividades passíveis de serem vividas e praticadas pelos professores das zonas rurais. As atividades denominadas então como periescolares ou pós-escolares, assim como as bibliotecas que, se não eram itinerantes, o eram da responsabilidade do professor da escola primária rural, e demais recursos que se atribuíam à responsabilidade do professor, foram no Paraná, enfaticamente recomendados.

Neste período, tais experiências foram pensadas e aplicadas na gestão de Erasmo Pilotto frente à pasta da Educação e Cultura, a partir de 1949. As propostas e experiências podem ser consideradas relevantes, uma vez que marcaram a vida dos professores e manifestavam as principais tendências presentes na educação internacional. As experiências locais realizadas na educação paranaense, no período acima citado, tiveram a peculiaridade de serem pensadas em função do habitante que se fez presente nas zonas rurais do Estado e principalmente nas glebas de café.

Quando nos deparamos com as fontes e com o que elas retratam, temos a clara impressão de reencontrarmos um pedaço do passado ainda pujante de vida. Assim, delas surgem as vozes daqueles que atuaram, viveram, pensaram e aplicaram ações que lhes pareceram as mais certas no atendimento às necessidades da população. Segundo Arlette Farge (1989) os personagens emergem do passado, e dão testemunhos de sua participação, de sua existência, do modo como perceberam determinados fatos e deles participaram.

$\mathrm{O}$ contato com as fontes referentes à educação paranaense no traz tais sentimentos. É este sentimento marcante que nos permite entender a singularidade das ações locais que foram pensadas e implantadas em função de alunos concretamente situados e inseridos em um contexto marcado pelo movimento gerado no calor da expansão capitalista da lavoura cafeeira.

$\mathrm{O}$ apelo para o sentimento gerado no contato com as fontes e as percepções das singularidades é registrado aqui como sustentação de algo que marcou os alunos e os professores que dirigiram os processos educativos não só no Paraná, como nas demais partes do Brasil, mas também em experiências educativas na América Latina. Erasmo Pilotto frente à política educacional paranaense, buscou em autores nacionais e internacionais, idéias e exemplos que pudessem ser aplicados com sucesso, na educação. Seu entusiasmo pela educação e a crença nas possibilidades de transformação social pela escola ficaram registrados em seus escritos, tomados aqui como documentos que testemunham como foi entendida e aplicada a proposta de educação rural no Paraná, especialmente na segunda metade da década de 40 do século XX. 
A influência do modelo mexicano das "missões culturais" constituiu-se em uma das marcas nas propostas de práticas nos cursos de formação de professores para as zonas rurais. Muitas experiências exitosas obtidas pelos países membros da UNESCO eram por ela recomendados para os demais países. Ainda, talvez as próprias experiências de Pilotto, lhe tenham feito buscar modelos de cunho social voltados para uma população prenhe de necessidades que iam além daquelas que a escola poderia suprir. A prática social moldava a teoria e direcionava-lhe o caminho. Um testemunho registrado por ele na obra "A educação é direito de todos" (1952), retrata o queremos dizer:

Quero, agora, contar alguns fatos de meu testemunho pessoal. Naquele dia, eu havia tentado reunir as professoras de um dos nossos municípios. Mas, tinham vindo apenas cinco ou seis, por causa de um desencontro de recados. Estávamos procurando ensinar-lhes duas ou três 'receitas', muito simples, para melhorarem a sua escola. Foi, então, a primeira vez que ouvi: 'Lá ninguém conta histórias para as crianças. As crianças nunca ouviram falar histórias'. Mas depois ouvi isto repetido não sei quantas vezes. Felizmente foi só naquela reunião que ouvi uma professora dizerme que os seus alunos não conheciam o pão (PILOTTO, 1952, p. 11)

A observação do meio e a vivência da realidade na qual as escolas estariam inseridas ${ }^{4}$ moldaram as propostas de sua organização e funcionamento, bem como de formação de professores para o meio rural. Foram as observações e o conhecimento do meio e das pessoas, os fatos que garantiram a singularidade de tais propostas. Se, em nível nacional, as diretrizes para os Cursos Normais Regionais já estavam apontadas na Lei Orgânica do Ensino Normal (1946), o modo como eram implantados, tanto os cursos de formação de professores como orientadas as práticas educativas, dependia da maior ou menor percepção e compreensão da vida e das necessidades da população de onde provinha a clientela escolar, bem como das condições materiais para sua implantação e vivência.

Os escritos de Pilotto sobre suas experiências como Secretário de Educação e Cultura, servem-nos de testemunho das ações então implantadas nas escolas rurais e empreendidas na formação de professores para tais escolas. Suas palavras são tomadas como testemunhos do intelectual que esteve à frente das ações apresentadas em um plano de trabalho que pretendia ser orgânico e buscava estabelecer a essência do trabalho do professor na zona rural. No entanto cabe ressaltar que tal testemunho representa a visão oficial. Quando estudamos a história recente, não podemos forçar os fenômenos a se repetirem, mas podemos reavivar nossas pistas. O historiador pode "literalmente, dar vida a algumas delas. São os relatos das testemunhas" (BLOCH, 2001, p. 74).

Deste modo, as impressões e sentimentos relatados por Pilotto frente às cenas provocadas pela colonização do norte paranaense, dizem da realidade para a qual as propostas de educação rural foram pensadas e vividas.

De outra vez, fui até uma das localidades, no norte do Estado, situada no extremo atingido, naquele momento, pela avalanche da penetração que, vinda dos outros Estados do Brasil e quási (sic!) de todos os outros Estados, vem, rasgando e queimando a selva, atrás de uma das prometidas Chanaãs (sic!) com que a natureza, de tempos em tempos, e em lugares diversos acena aos homens com o lenço da esperança das fortunas vertiginosas e tantas vezes é apenas a fortuna de uns poucos e a ansiedade e a busca inquieta de todos aqueles nômades. Pude ver, então: 
o chão ainda se conservava cálido do fogo recente que destruíra a mata para dar lugar à cultura do café. $\mathrm{O}$ fogo não se havia ainda apagado de todo. E ali estavam homens morando em casas feitas com a madeira que, cortada na ante-véspera, ainda tinha seiva, os troncos toscos das árvores amarrados uns aos outros. Uma família inteira em uma cobertura de palha, sem paredes. Barracas de lona. O fogão ainda ao ar livre na semeadura de verdadeiro acampamento. O café, plantado, precisa quatro ou cinco anos para começar a produzir. E, muitos, (falo agora com um preto rude e moço vindo de Minas), não são donos da terra. Nunca o serão. Nem pensam em sê-lo. Já vieram com vontade só de serem empregados. E mais de duzentas famílias já estão morando aqui, vindas no último ano, mas não moram neste lugar onde agora o favorecido dono da empresa de colonização está levantando a igreja onde nenhum padre vai vir ainda por muito tempo. Onde moram, então? 'Aí pelos matos', Cada sítio está separado dos outros sítios pelo mato, - a selva selvagem. Cada homem está separado dos outros homens. Aqui não há nada mais do que a mata para vencer, a terra como um prodígio, e homens nômades talvés (sic!) pela esperança. Penso na escola que é preciso levantar aqui. Que educação devemos àquela criança que ali está, na minha frente, - a escola talvés (sic!) tarde ainda a chegar e, quando chegar, que escola vai ser? Em frente de mim, está u'a mulher grávida e tem vinte anos. (PILOTTO, 1952, p. 12)

Ainda, as vozes dos professores contidas nas cartas retratadas no livro que aborda "problemas, reflexões e soluções sobre a educação pública paranaense" (Pilotto, 1952, prólogo) no período, dão consistência ao depoimento e possibilitam sabermos da história da formação dos professores e de sua atuação nas zonas rurais.

Em 1953, a Recomendação no 36 da UNESCO aos Ministérios da Instrução Pública, concernente à Formação do Professor Primário, no item 13 do título "Organização e administração do ensino primário", sugeria que:

[...] Là où il existe um système de formation distinct pour lês maîtres ruraux et pour lês maîtres urbains, il importe d'assurer, par l'équivalence du niveau des études, l'équivalence des titres qui sont conferes aux uns et aux autres. (UNESCO. Recommandations, 1977, p. 116)

Com esta recomendação, a UNESCO reforçava a necessidade de que a equivalência de formação para os mestres das zonas rurais e urbanas fosse o mais possível, garantida.

\section{As missões culturais mexicanas e a formação dos professores para as zonas rurais}

Ao deparar-se com a vastidão de terras para as quais se encaminhavam os migrantes de Minas Gerais, Bahia e de outros estados brasileiros que vinham em busca de terra e de trabalho, assim como os imigrantes japoneses, e inserido na política estadual de ocupação do território paranaense, o Secretário de Educação e Cultura, Prof. Erasmo Pilotto buscou no modelo mexicano das missões culturais, algumas linhas de condução para a organização da escola que se fazia necessária. Tais linhas de condução inspiravam também os principais educadores brasileiros que se preocupavam com o processo de 
interiorização dos cursos de formação de professores. Dentre estes educadores salienta-se Lourenço Filho.

O Relatório que este educador apresentou ao Ministro da Educação e Saúde em dezembro de 1951 e que foi publicado na Revista Brasileira de Estudos Pedagógicos (jan/mar, 1952, nº45) traz um amplo estudo sobre a educação rural no México e o modelo de educação lá aplicado. As semelhanças trazidas pelos desafios de alfabetizar e escolarizar os habitantes das zonas rurais, desafio comum aos países então considerados subdesenvolvidos constituía-se em preocupação desses países e traduzia-se nas políticas para os cursos normais regionais.

O caráter missionário do trabalho do professor e a perspectiva de que seu trabalho seria capaz de transformar a sociedade, presentes no modelo das missões culturais, acompanhou a proposta dos cursos normais regionais no Paraná.

Neste Estado, a formação de professores apropriou-se dessa intenção, com uma diferença fundamental: enquanto no México, as missões culturais, em um primeiro momento, estiveram vinculadas ao problema agrário de divisão da terra e muitos professores tenham se transformado em mártires, no Paraná, o caráter do trabalho pedagógico foi inserido no processo de redemocratização após a ditadura de 1938-1945. No estado paranaense, embora a proposta acolhesse aspectos preponderantemente técnicos, como a aprendizagem pelos futuros professores, das técnicas de cultivo do solo e de conservação dos alimentos, priorizava também a formação geral, ou seja, a transmissão da cultura geral ao trabalhador rural. Esta entendida como a transmissão daquilo que os homens em sua história, tivessem produzido de mais aprimorado, no campo da cultura mais elaborada. Por esta linha, aproximava-se do grupo de educadores que consideravam a necessidade de outras medidas sociais além da ação educacional, como necessárias à solução dos problemas sociais, como veremos mais adiante.

Assim, tal característica não foi comum a todos os cursos normais regionais implantados no Brasil. A preocupação com a educação geral ao lado do domínio de técnicas de ensino, principalmente de alfabetização, era componente do projeto paranaense, mas não da Escola Normal Regional de Juazeiro, por exemplo. Nesta, o futuro professor deveria aprender o básico para ensinar seus alunos a lerem, escreverem e contarem e eram privilegiadas as técnicas de trabalho rural, do trato da terra, da produção e do cultivo agrícolas.

Aliás, como bem apontou Lourenço Filho em estudo preparado para a UNESCO (1952)5 intitulado: "Preparação de pessoal docente para escolas primárias rurais" (1953), naquele período (décadas de 40 e 50) duas correntes de educadores tinham perspectivas diferentes sobre a possibilidade transformadora da educação na sociedade. A primeira afirmava a eficiência da preparação técnico-agrícola, aliada à preparação em higiene e profilaxia, dos mestres rurais. Esta preparação possibilitaria que o professor transformasse o homem do campo em melhor produtor rural e assim colaborasse para o desenvolvimento da sociedade.

A segunda, exposta por alguns professores universitários e pensadores sociais, considerava que "não se poderia admitir a fórmula simplista de que a educação elementar pudesse 'fixar o homem no campo' desde que ensinasse [...] rudimentares técnicas agrícolas e de defesa da saúde" (LOURENÇO FILHO, 1953, p. 66). Para esses educadores, a escola primária não deveria dar nenhum tipo de ensino de caráter profissional. $\mathrm{O}$ problema careceria de medidas de maior envergadura:

[...] reforma do regime agrário; desenvolvimento não só dos serviços de fomento da produção agrícola como de distribuição de crédito e defesa da 
produção; melhoria das vias de comunicação e serviços de assistência; serviços de educação de adolescentes e adultos analfabetos; 'missões rurais' com o emprego de processos técnicos modernos de difusão, como os do cinema, e, enfim, melhoria das instalações escolares, construção de casas de residência para os professores, organização regional de sua formação, com atenção às necessidades gerais de vida em cada ambiente (LOURENÇO FILHO, 1953, p. 66)

Pilotto, à frente da Secretaria de Educação e Cultura e envolvido com a questão de que tipo de educação dar às crianças filhas de migrantes que ocupavam o território paranaense, comungava do grupo defensor de uma educação geral, humanista. Dizia ele (s/d) que estava errado pensar em fazer da criança um pescador, somente porque ela havia nascido junto ao mar e talvez fosse ali viver. A tarefa do professor era dar aos seus alunos uma educação geral e "transformar a sua escola em centro de educação especializada" (s/d, p. 108). Referia-se ele à forma de trabalho diferenciado que o professor primário deveria ter considerando o meio no qual vivia seu aluno, pois os problemas que o professor tinha que resolver eram muito diferentes daqueles da escola urbana ou situada no campo.

A função da escola primária era a de fazer com que as crianças que lhe estavam confiadas "vivessem cada vez mais como homens", ou seja, vivessem cada vez melhor.

Ao redigir o programa das escolas isoladas recomendava:

Nesta primeira parte deste programa das escolas isoladas, nós dizemos que o único programa é o de fazer estas crianças chegarem a viver uma vida melhor, chegarem a viver como homens. E tudo que constar de um programa escolar não deve ser sinão (sic!) com a preocupação de auxiliar o professor a resolver esse problema, a cumprir essa diretriz. $\mathrm{O}$ verdadeiro programa é esse. O mais são instruções para realizá-lo (PILOTTO, s/d, p.106-107).

Os professores que recebiam estas orientações, em sua grande maioria não tinham formação de magistério e constituíram a clientela dos cursos normais regionais. Estes cursos foram implantados com a intenção de formar o professor como o mediador das transformações no meio rural, colaborando para a diminuição da evasão do campo e formação do trabalhador produtivo alfabetizado. Para auxiliar as escolas rurais a cumprirem a missão que o governo lhe atribuía, Pilotto propôs a Associação dos Amigos da Escola (atividade periescolar), dentre outras atividades escolares que poderiam e deveriam ser organizadas, pois à escola estava destinado o papel de centro irradiador da cultura.

A Associação dos Amigos da Escola deveria ter uma organização bem simples para reunir em torno de si os vizinhos que se dedicariam a "um trabalho de fomento à Educação e amparo à obra educativa" (PILOTTO, 1952, p. 39). Segundo ele, tais idéias lhe foram inspiradas pelas missões culturais mexicanas. E ele as tomou como paradigma para a expansão do ensino no meio rural, reunindo professores leigos para ensinar-lhes noções pedagógicas básicas com a intenção de que, por meio da aplicação das mesmas, a escola rural cumprisse seus objetivos. Chegou mesmo a redigir um plano para o funcionamento dessas Associações, que denominou "Plano para uma Associação Funcional".

O Plano constava de 3 artigos, 5 anexos e várias sugestões de atividades tais como teatros, festas, bailes, modos de estudar o meio no qual a escola estava situada e associação de ex-alunos para que os professores não perdessem contato com aqueles que já haviam 
concluído o curso primário. No anexo 1 estava explicitado o conceito de escola rural e sua função. Dizia o mesmo:

\begin{abstract}
A escola rural contribui para o desenvolvimento do estado econômico da comunidade organizando os vizinhos para procurar um maior rendimento do solo, para obter caminhos e comunicação postal, telegráfica e telefônica, procurando mercados para os produtos e implantando novas culturas para que sirvam como unidades de demonstração para os camponezes (sic!). A criação de animais (galinhas, pombas, abelhas, coelhos, cabras, etc.), constitui também um elemento de demonstração e de propaganda, com o fim de desenvolver o estado econômico (PILOTTO, s/d, p. 109-110)
\end{abstract}

Também as funções expostas acima guardam similaridade com as previstas para serem desenvolvidas pelas escolas normais campesinas mexicanas, a partir de 1930. Segundo Civera (2007):

En las excursiones de observación e investigación, los alumnos indagaban sobre el tipo de tierras de la zona, los cultivos y harramientas de labranza que se utilizaban, los salarios o los tipos de posesión de tierra, las condiciones de las vias de comunicación y de los servicios de agua o luz, así como las características de la fauna, flora y clima. La observación, la investigación y la experiencia eran consideradas de gran importancia (CIVERA, 2007, p. 438).

Retomando o Plano apresentado por Pilotto, o anexo 1 sugeria que o professor criasse na escola, animais de pequeno porte e oferecesse os filhotes aos alunos para que os criassem em casa, com a condição de não matá-los ou vendê-los. Ao contrário, quando os mesmos já estivessem crescidos, deveriam ser devolvidos à escola para que ela os comercializasse e o lucro fosse dividido entre os alunos em sistema de cooperativas.

A idéia de cooperativas também estava presente no modelo de escolas rurais mexicanas. Segundo Civera, a partir de 1932, "se fomentaba el cooperativismo como un sistema no solo para obtner créditos sino también como um laboratório de solidariedad social" (2007, p. 429).

Pode-se perceber que o que se esperava da escola e do trabalho do professor ultrapassava suas reais possibilidades. Esta constatação foi feita pelo próprio Pilotto, mais tarde ao rever sua ação pedagógica. Segundo ele, tais sugestões eram exatas nas intenções, mas ingênuas, pois a escola não tinha força para modificar o meio ambiente. (Pilotto, 1959).

Ainda, as missões culturais mexicanas inspiraram atividades promovidas nos cursos normais colegiais, voltadas para um sentido social e que também foram chamadas de missões culturais. As alunas embarcavam em um caminhão e dirigiam-se a um núcleo rural. Neste já havia sido previamente articulado com o professor local, a propaganda da visita das alunas e os convites aos moradores. As alunas desenvolveriam então um programa previamente traçado: "teatro para adultos, teatrinho de fantoches para as crianças, exposição de pintura, de arte fotográfica, roda de histórias para as crianças, canto coral, audição de discos" (PILOTTO, s/d, p.129). Levariam alguém que ensinasse ou "induzisse" principalmente as mulheres a aproveitarem as frutas "em uma produção 
cooperativa de geléias" (Pilotto, s/d, p. 129). Ainda procurariam transmitir cuidados higiênicos, e demais atendimentos às necessidades da comunidade.

O entusiasmo com que o modelo de cursos normais regionais foi implantado, inspirando-se nas ideias das missões culturais mexicanas e ainda em demais autores (Pestalozzi, dentre outros) que consideravam o valor transformador da educação na sociedade, foi singular na educação paranaense.

Há a ressaltar que as considerações sobre as escolas rurais mexicanas e as missões culturais quando trazidas por Lourenço Filho representam a leitura de um educador-técnico que estava em busca de ideias e modelos para resolver os problemas de analfabetismo, cuidados higiênicos, sanitários e melhor produção do habitante rural. Porém, foi marcante sua influência sobre a educação paranaense, sobretudo em relação às escolas normais regionais.

No entanto, as políticas e as práticas norteadoras da formação e da ação do professor articulavam-se no plano nacional e internacional, não só seguindo modelos inspiradores de novas ações, mas buscavam seguir o que era recomendado pela UNESCO, como já nos referimos anteriormente.

\section{REFERÊNCIAS}

BRASIL. Decreto-Lei $n^{\circ}$ 8530, de 02 de jan. de 1946. Aprova a Lei Orgânica do Ensino Normal. Diário Oficial da União $n^{\circ}$ 03, 04 jan. 1946.

BLOCH. M. Apologia da história ou o ofício do historiador. Rio de Janeiro: Jorge Zahar, 2001.

CIVERA.C. Entre el Campo y la Ciudad: la formación de maestros normalistas rurales y técnicos agrícolas em México, 1921 - 1945 (p.425 -454) in WERLE. F.O. C. (org.) Educação rural em perspectiva internacional. Ijuí -RS: Editora Unijuí, 2007.

FARGE. A. Le goût de l'archive. Paris, Éditions du Seuil, 1989.

LOURENÇO FILHO. M.B. A educação rural no México. Revista Brasileira de Estudo Pedagógicos. (INEP). São Paulo: Empresa Gráfica Revista dos Tribunais, 1952, vol.XII, jan-mar, $n^{\circ} 45$.

LOURENÇO FILHO. M. B. Preparação de pessoal docente para escolas primárias rurais. Revista Brasileira de Estudo Pedagógicos. (INEP). São Paulo: Empresa Gráfica Revista dos Tribunais, 1953, vol.XX, out-dez, n ${ }^{\circ} 52$.

MIGUEL. M. E. B. A formação do professor e a organização social do trabalho. Curitiba: Editora da UFPR, 1997.

PILOTTO. E. A educação é direito de todos. Curitiba: Max Roesner, 1952.

PILOTTO.E. Prática da Escola Serena. Curitiba: João Haupt, s/d.

PILOTTO.E. Situação do desenvolvimento brasileiro e a educação. Curitiba: Associação de Estudos Pedagógicos, 1959. 
UNESCO. Recommandations 1934-1977. Conference Internationale do l'education. France: Imprimerie de la Manutention à Mayenne, 1979.

\section{Notas}

1. Decreto Lei $N^{\circ} .8530$ - de 02 de janeiro de 1946.

2. Por não haverem cursado o Normal, ou mesmo por terem feito somente o curso primário.

3. A respeito da organização dos Cursos Normais Regionais no Paraná, no período, ver: A formação do professor e a organização social do trabalho. MIGUEL, M. E. B., Editora UFPR: Curitiba, 1997.

4. Muitas escolas ainda precisavam ser criadas e providas.

5. O estudo preparado para a UNESCO foi publicado pela mesma em francês e inglês, com o título: La formatión Professionelle du Personnel Enseignant Primaire (LOURENÇO FILHO, 1953, p.61).

Recebido em: 10/10/11

Aprovado em: 13/11/11 